\title{
Progress in Chemical Compositions and Pharmacological Activities of Althaea officinalis
}

\author{
Tao-Tao Xue, ${ }^{a}$ Hong-Bo Xu, ${ }^{*, a}$ Zhi-Shu Tang, ${ }^{*, a}$ Jin-Ao Duan ${ }^{a, b}$ Hong-Bo Liu, ${ }^{a}$ Xin-Bo Shi, ${ }^{a}$ \\ and Zhong-Xing Song ${ }^{a}$ \\ ${ }^{a}$ Co-construction Collaborative Innovation Center for Chinese Medicine Resources Industrialization by Shaanxi \\ \& Education Ministry, State Key Laboratory of Research \& Development of Characteristic Qin Medicine \\ Resources (Cultivation), Shaanxi University of Chinese Medicine, Xianyang, Shaanxi 712083, China \\ ${ }^{b}$ Jiangsu Collaborative Innovation Center of Chinese Medicinal Resources Industrialization, \\ Nanjing University of Chinese Medicine, Nanjing, Jiangsu 210023, China
}

Email: xhb2005@sntcm.edu.cn (H. X.), tzs6565@163.com (Z. T.)

\begin{abstract}
Althaea officinalis (Malvaceae), mainly distributed in Europe and China, is an ornamental, edible and medicinal plant, which is effective in reducing cough and phlegm. To better develop and utilize $A$. officinalis, 46 kinds of compounds including flavonoids, phenolic acids, steroids, coumarins and other types isolated from this plant are summarized, and their pharmacological effects such as anti-tussive, anti-inflammatory, anti-oxidation, anti-bacterial and anti-fungal activities are discussed in this review.
\end{abstract}

Keywords Althaea officinalis, flavonoids, anti-tussive, anti-oxidation

\section{Introduction}

Althaea officinalis L. (Malvaceae), commonly known as marshmallow, is a perennial herb which is native throughout damp areas of Europe and Asia. ${ }^{[1,2]}$ The roots, leaves and flowers of this plant are usually used as food and medicine in many countries all over the world. For example, the root of $A$. officinalis is used traditionally for the treatment of irritation of oral and pharyngeal mucosa, dry cough, mild gastritis, skin burns, insect bites, catarrh, ulcers, abscesses, constipation and diarrhea. $^{[3]}$ Modern pharmacological studies revealed that $A$. officinalis showed anti-tussive, anti-oxidant, anti-inflammatory, anti-estrogenic, anti-microbial, immunomodulatory, anti-urolithiasis and cytotoxic activities. ${ }^{[1]}$ It mainly contained mucilage, flavonoids, polysaccharides and phenolic acids. ${ }^{[3]}$ Until now, its chemical compositions and pharmacological effects have not been systematically sorted out. This review, containing 43 references related to traditional usage and modern research, provides a systematic overview of $A$. officinalis. Besides, the possible research directions in the future are discussed in the article.

\section{Chemical Constituents}

Researchers have isolated and identified 46 compounds from different parts of this plant, including flavonoids, phenolic acids, coumarins, steroids and amino acids, etc.

Flavonoids are the main ingredients of $A$. officinalis. At present, a total of 17 flavonoids were obtained from the plant, and they are tiliroside (1), ${ }^{[4]}$ kaempferol 3-glucoside (2) ${ }^{[4]}$ quercetin 3 -glucoside (3), ${ }^{[4]}$ hypolaetin-8-glucoside (4), ${ }^{[5]}$ hypoletin-8- $\beta$-gentiobioside (5), ${ }^{[5]}$ astragalin $(6),{ }^{[6]}$ kaempferol 7-O-glucoside (7), ${ }^{[6]}$ hypolaetin-8-O- $\beta$ - $D$-(2"-O-sulfo)-glucopyranoside $(8),{ }^{[7]} \quad 4$ '-O-methylhypolaetin-8-O- $\beta$ - $D$-(2"-O-sulfo)glucopyranoside (9), ${ }^{[7]} \quad 4^{\prime}$-O-methylhypolaetin-8-O- $\beta-D-\left(3^{\prime \prime}-O\right.$ sulfo)-glucuronopyranoside (10), ${ }^{[7]} 4^{\prime}$-O-methylisoscutellarein8-O- $\beta$ - $D$-(3"-O-sulfo)-glucuronopyranoside (11), ${ }^{[7]}$ hypolaetin-8$O-\beta-D-\left(3^{\prime \prime}-O\right.$-sulfo)-glucuronopyranoside (theograndin II) (12), ${ }^{[7]}$
hypolaetin-8-O- $\beta$ - $D$-glucopyranosyl-(1"' $\rightarrow 4$ ")- $\beta$ - $D$-glucuronopyra noside (13), ${ }^{[7]}$ quercetin (14), ${ }^{[8]}$ kaempferol $(15),{ }^{[8]}$ hypolaetin 8-O- $\beta$ - $D$-glucoside (16), ${ }^{[9]}$ isoscutellarein 4 '-methyl ether 8-O- $\beta$ - $D$-glucoside-2"- $\mathrm{SO}_{3} \mathrm{~K}$ (17). ${ }^{[9]}$ Among them, 8-11 are new compounds isolated from the roots of $A$. officinalis for the first time. The structures of these compounds were shown in Figure 1.

In addition, previous studies revealed that $A$. officinalis contained steroids, triterpenoids, coumarins, phenolic acids, tannins, amino acids and other compounds. Until now, 1 steroid and 1 triterpenoid were isolated from the roots and seeds, which were identified as $\beta$-sitosterol $(\mathbf{1 8})^{[10,11]}$ and lanosterol $(19),{ }^{[10]}$ respectively. Three coumarins were separated from the roots and identified as 5,6-dihydroxycoumarin-5-dodecanoate$6 \beta$-D-glucopyranoside $\quad(20),{ }^{[10]}$ scopolin-6'-O- $\alpha$ - L-rhamnopyranoside $(\mathbf{2 1})^{[7]}$ and scopoletin (22). ${ }^{[3,9]}$ The structures of these compounds were shown in Figure 2.

Other types of compounds were also isolated from $A$ officinalis and respectively identified as caffeic acid (23), ${ }^{[6,9]}$ 4-hydroxybenzoic acid (24), ${ }^{[3,6,9]}$ ferulic acid (25), ${ }^{[6,9]}$ 4-hydroxycinnamic acid $(\mathbf{2 6}),{ }^{[3,6,9]}$ vanillic acid $(\mathbf{2 7}),{ }^{[6,9]}$ chlorogenic acids (28), ${ }^{[6]} \quad N-(E)$-caffeoyl-L-dopa (29) ${ }^{[7]} N-(E)$-caffeoyl-L-tyrosine (30), ${ }^{[7]} \quad \mathrm{N}-(E)$-coumaroyl-L-dopa $(31),{ }^{[7]} \quad \mathrm{N}-(E)$-coumaroyl- $L$ tyrosine (32), ${ }^{[7]}$ salicylic acid (33) ${ }^{[3,9]} p$-hydroxyphenylacetic acid (34), ${ }^{[3,9]}$ lauric acid (35), ${ }^{[10]} n$-hexacos-2-enyl-1,5-olide (36), ${ }^{[10]} \quad 2 \beta$-hydroxycalamene $(37),{ }^{[10]} n$-triacontanoic acid (38), ${ }^{[11]} \quad 3,4$-dihydroxybenzyl octadecane (39), ${ }^{[11]} 24 \beta$, 28 $\beta$-dihydroxy octa tetracont-36-en-1-oic-acid (40), ${ }^{[11]}$ $n$-tetracosane $(\mathbf{4 1}),{ }^{[11]} 5 \beta, 13 \beta$-dihydroxynonacosanyl godoleate $(42),{ }^{[11]} n$-pentatriacontane $(43),{ }^{[11]}$ diglucosyl oleate $(44),{ }^{[11]}$ $\mathrm{N}$-(E)-cinnamoyl-L-aspartate $(45)^{[7]}$ and glycine betaine $(46){ }^{[7]}$ Among them, 36, 37, 39, 40 and 42 are new natural products isolated from the seeds and roots of $A$. officinalis. The structures of these compounds were shown in Figure 3.

Furthermore, polysaccharides were also found from $A$. officinalis by researchers. ${ }^{[12-17]}$ 
<smiles>O=C(/C=C/c1ccc(O)cc1)OC[C@H]1O[C@H](Oc2c(-c3ccc(O)cc3)oc3cc(O)cc(O)c3c2=O)[C@H](O)[C@@H](O)[C@H]1O</smiles>

1<smiles>O=c1cc(-c2ccc(O)c(O)c2)oc2c(O[C@@H]3O[C@H](CO)[C@@H](O)[C@H](O)[C@H]3O)c(O)cc(O)c12</smiles><smiles>O=c1c(O)c(-c2ccc(O)cc2)oc2cc(O[C@@H]3O[C@H](CO)[C@@H](O)[C@H](O)[C@H]3O)cc(O)c12</smiles><smiles>O=C(O)C1OC(Oc2c(O)cc(O)c3c(=O)cc(-c4ccc(O)c(O)c4)oc23)[C@H](O)[C@@H](O)[C@@H]1O[C@H]1OC(CO)[C@H](O)C(O)[C@H]1O</smiles>

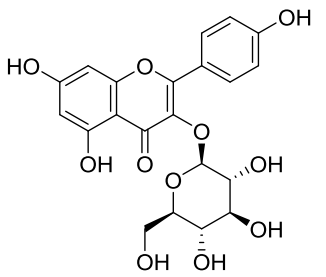

2

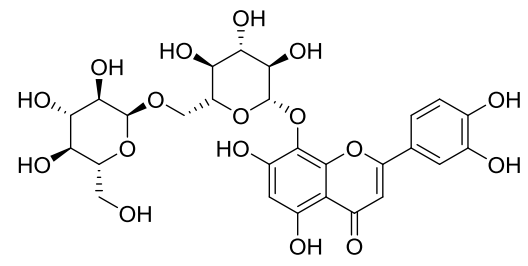<smiles>O=c1c(OC2OC(CO)[C@@H](O)C(O)[C@H]2O)c(-c2ccc(O)c(O)c2)oc2cc(O)cc(O)c12</smiles>

3

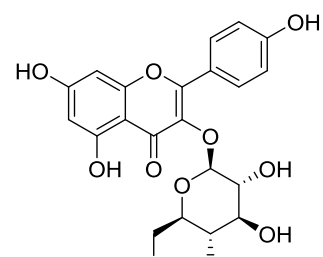

$\mathrm{OH} \quad \overline{\mathrm{O}}$

$\mathrm{OH}$

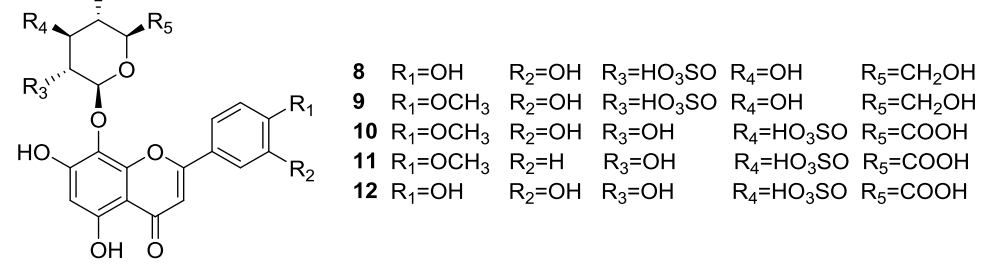<smiles>[R]c1cc(-c2oc3cc(O)cc(O)c3c(=O)c2O)ccc1O</smiles>

$14 \mathrm{R}=\mathrm{OH}$

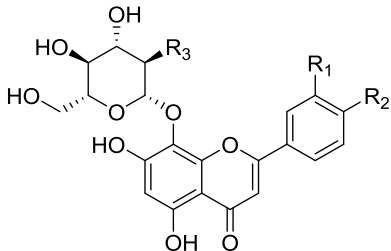

$16 \mathrm{R}_{1}=\mathrm{OH} \quad \mathrm{R}_{2}=\mathrm{OH} \quad \mathrm{R}_{3}=\mathrm{OH}$

$17 \quad \mathrm{R}_{1}=\mathrm{H} \quad \mathrm{R}_{2}=\mathrm{OCH}_{3} \quad \mathrm{R}_{3}=\mathrm{OSO}_{3}^{-} \mathrm{K}^{+}$

Figure 1 Flavonoids isolated from Althaea officinalis.

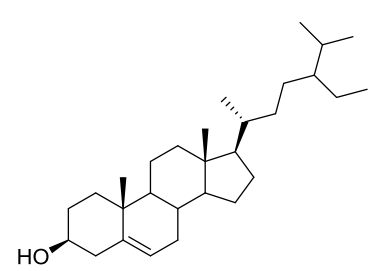

18

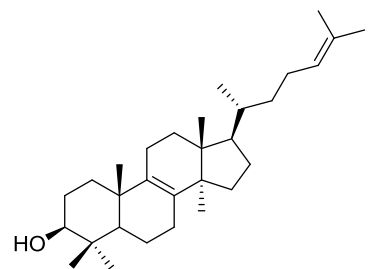

19<smiles>CCC(=O)Oc1c(O[C@@H]2O[C@H](CO)[C@@H](O)[C@H](O)[C@H]2O)ccc2oc(=O)ccc12</smiles>

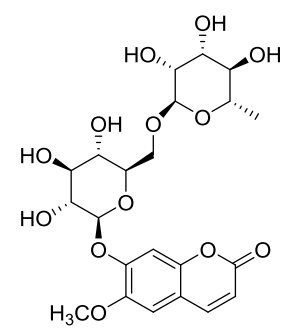

21

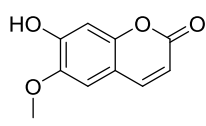

22

Figure 2 Steroid, triterpenoid and coumarins isolated from Althaea officinalis. 
<smiles>O=C(O)/C=C/c1ccc(O)c(O)c1</smiles>

23<smiles>COc1cc(/C=C/C(=O)O)ccc1O</smiles>

25<smiles>O=C(O)/C=C/c1ccc(O)cc1</smiles>

26<smiles>O=C(O)c1ccc(O)cc1</smiles>

24<smiles>COc1cc(C(=O)O)ccc1O</smiles>

27<smiles>O=C(/C=C/c1ccc(O)c(O)c1)O[C@H]1C[C@@](O)(C(=O)O)C[C@H](O)[C@H]1O</smiles>

28<smiles>[R]c1cc(/C=C/C(=O)N[C@@H](Cc2ccc(O)c([R2])c2)C(=O)O)ccc1O</smiles>

$29 \mathrm{R}_{1}=\mathrm{OH} \quad \mathrm{R}_{2}=\mathrm{OH}$

$30 \mathrm{R}_{1}=\mathrm{OH} \quad \mathrm{R}_{2}=\mathrm{H}$

$31 \mathrm{R}_{1}=\mathrm{H} \quad \mathrm{R}_{2}=\mathrm{OH}$

$32 \mathrm{R}_{1}=\mathrm{H} \quad \mathrm{R}_{2}=\mathrm{H}$<smiles>O=C(O)c1ccccc1O</smiles>

33<smiles>O=C(O)Cc1ccc(O)cc1</smiles>

34<smiles>CCCCC1(C)C=CC(=O)OC1</smiles>

36<smiles>Cc1ccc2c(c1)[C@H](C(C)C)C[C@@H](O)[C@H]2C</smiles>

37

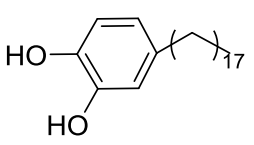

39<smiles>CCCCCCCC(O)CCC(O)CC(=O)O</smiles>

40<smiles>CCC=CCC(=O)OCCC(C)(O)CC(C)(O)CC</smiles>

42<smiles>O=C(O)C[C@H](NC(=O)/C=C/c1ccccc1)C(=O)O</smiles>

45<smiles>C=C([O-])C[N+](C)(C)C</smiles>

46

Figure 3 Other compounds isolated from Althaea officinalis.

\section{Pharmacological Activities}

A. officinalis has shown multiple pharmacological effects in vitro and in vivo such as anti-tussive, anti-inflammatory, anti-oxidation, anti-bacterial and anti-fungal activities, and so on.

\section{Anti-tussive effects}

A. officinalis has a long history as a traditional medicine for the treatment of cough and other respiratory problems. The German Standard License approved $A$. officinalis root tea for soothing irritation due to mucosal inflammation of the pharynx and upper respiratory tract, ${ }^{[18]}$ meanwhile, cough preparations containing aqueous extracts of $A$. officinalis roots also played an important role in cough treatment.

In a clinical trial, Fink et al. ${ }^{[19]}$ carried out an independently survey on patients $(n=822)$, who received oral administration of the aqueous extracts obtained from $A$. officinalis roots. The results of survey indicated that the aqueous extracts showed a good effect on the symptomatic treatment of oral or pharyngeal irritation with a very rapid onset of effects within $10 \mathrm{~min}$ in the majority of cases.

Related researches showed the mucilage polysaccharide content of $A$. officinalis was $6.2 \%-11.6 \% .^{[20]}$ In order to investigate the effectiveness of the mucilage polysaccharides as an anti-tussive and anti-cough agent, the polysaccharides and rhamnogalacturonan isolated from $A$. officinalis roots and flowers were tested for anti-tussive activity in unanesthetized cats and guinea pigs of both sexes at oral doses of 50 to 100 $\mathrm{mg} / \mathrm{kg}$ body weight, ${ }^{[21-24]}$ in a cough induced by mechanical stimulation, both polysaccharides and rhamnogalacturonan significantly reduced the intensity, the frequency and the number of cough efforts from laryngopharyngeal and tracheobronchial areas. The anti-tussive mechanism might be explained as mucilaginous herbs like $A$. officinalis roots could form a protective film on the respiratory mucosa thereby to prevent it from being stimulated by foreign antigens. ${ }^{[18]}$

\section{Anti-inflammatory effects}

Bonaterra et al. ${ }^{[25]}$ studied the anti-inflammatory effects of root extracts of $A$. officinalis on Macrophages $(M \varphi)$ in vitro using the THP-1 (human acute monocytic leukemia) cell line. The 
enzyme-linked immunosorbent assay results displayed that the extracts possessed potent inhibitory effects on LPS-induced release of tumor necrosis factor-alpha (TNF- $\alpha$ ) and interleukin-6 (IL-6). The extracts were also found to protect human $\mathrm{M} \varphi$ against $\mathrm{H}_{2} \mathrm{O}_{2}$-induced cytotoxicity and cellular reactive oxygen species production, additionally improving the migratory capacity of the cells.

\section{Anti-oxidation effects}

Regarding the anti-oxidant activity of $A$. officinalis, many studies have been carried out in vitro. Benbassat et al. ${ }^{[26]}$ and Zaghlool et al. ${ }^{[27]}$ evaluated the anti-oxidant activity of roots extracts prepared with different extraction solvents applying ABTS, DPPH, hypochlorous acid scavenging and iron-induced lipid peroxidation assays. They found the water extracts possessed weak anti-oxidant activity, whereas the ethanol extracts showed well pronounced anti-oxidant activity. Moreover, the anti-oxidant properties of $A$ officinalis flowers ethanolic extracts were evaluated using different anti-oxidant tests in vitro, ${ }^{[28]}$ at the concentration of 50,100 , and $250 \mathrm{mg} / \mathrm{mL}$. The extracts showed $85.5 \%, 91.2 \%$, and $96.4 \%$ inhibition on peroxidation of linoleic acid emulsion, respectively. Furthermore, the extracts had effective reducing power, free radical scavenging, superoxide anion radical scavenging, and metal chelating activities at same concentration (50, 100, and 250 $\mathrm{mg} / \mathrm{mL}$ ).

The polysaccharides $(1.0-5.0 \mathrm{mg} / \mathrm{mL})$ obtained from ethanolic extracts of $A$. officinalis flowers were further investigated for anti-oxidant activity by Tabarsa et al. ${ }^{[29]}$ The $\mathrm{IC}_{50}$ values of DPPH assay and ferric iron reducing assay were 4.77 and $3.10 \mathrm{mg} / \mathrm{mL}$, respectively. A recent study ${ }^{[30]}$ showed the polysaccharides isolated from $A$ officinalis leaves illustrated a high degree of hydroxyl radical scavenging capacity with an $I_{50}$ of $9.7 \mathrm{mg} / \mathrm{mL}$. It was also found that the scavenging effect of polysaccharides on DPPH radicals increased linearly with increased concentration $(0-20 \mathrm{mg} / \mathrm{mL})$, showing $93.4 \%$ inhibition at a concentration of $20 \mathrm{mg} / \mathrm{mL}$.

In addition, Sadighara et al. ${ }^{[31]}$ discovered that the anti-oxidant capacities of $A$. officinalis varied from strong to weak according to the plant colors (reddish-pink, pink, white) by CUPRAC and ferric iron-reducing assays.

\section{Anti-bacterial and anti-fungal activities}

The extracts of $A$. officinalis from different parts showed good anti-microbial activity. The $70 \%$ ethanolic extracts of $A$. officinalis roots were found to be against Streptococcus mutans and Lactobacillus acidophilus. The minimum inhibitory concentration (MIC) for $S$. mutans and $L$. acidophilus were 102.0 and $212.5 \mathrm{mg} / \mathrm{mL}$, respectively. ${ }^{[32]}$ Moreover, the ethanolic extracts also showed an inhibitory effect on Pseudomonas aeruginosa by an agar well plate test, ${ }^{[33]}$ and the MIC and minimum bactericidal concentration (MBC) was 62.5 $\mathrm{mg} / \mathrm{L}^{[33]}$

Jafari-Sales et al. ${ }^{[34]}$ explored the anti-bacterial effect of ethanolic extracts extracted from $A$. officinalis stems and leaves on antibiotic-resistant strains of Staphylococcus aureus. The obtained MIC and MBC were 3.2 and $6.5 \mathrm{mg} / \mathrm{mL}$ by agar dilution method, respectively. Additionally, the hydroalcoholic extracts of leaves of $A$ officinalis were efficacious against gram-positive bacteria, while they were not effective on gram-negative bacteria at the tested concentrations. ${ }^{[35]}$ The extracts of $A$ officinalis can be a great candidate for the treatment of gram-positive infections, which are worthy of further study.

Khamees et al. ${ }^{[36]}$ investigated aqueous extracts $(300-400$ $\mathrm{mg} / \mathrm{mL}$ ) and methanol extracts $(100-400 \mathrm{mg} / \mathrm{mL}$ ) of flowers of $A$. officinalis, and the results exhibited valuable antibacterial effects against gastrointestinal pathogens ( $S$. aureus, Escherichia coli, Salmonella typhimurium, Klebsiella pneumonia, Plasmodium vulgaris and Streptococcus dysentery) in vitro. Especially, the methanol extracts were found to possess more potent inhibition effects on the growth of bacteria species. In addition, Valiei et al. ${ }^{[37]}$ discovered that the hexane extracts of $A$. officinalis from flowers and roots exhibited good anti-microbial activities against $E$. coli, Pseudomonas aeruginosa, K. pneumoniae, Bacillus subtilis, Enterococcus faecalis, S. aureus and Staphylococcus epidermidis in vitro by the disc diffusion method (DDM).

The $A$. officinalis seed extracts and essential oil were screened for anti-microbial activity by Gautam et al. ${ }^{[38]}$ The essential oil possessed significant inhibition activities against Streptococcus pyogenes $(21.3 \pm 0.28 \mathrm{~mm})$ and Haemophilus influenzae $(19.0 \pm 0.50 \mathrm{~mm})$ at $200 \mathrm{mg} / \mathrm{mL}$. Meanwhile, the essential oil and the aqueous extracts showed higher anti-fungal activities on Aspergillus niger with inhibition rates of $41.28 \%$ and $36.27 \%$.

\section{Anti-ulcer effects}

In order to investigate the protective effects of extracts of $A$. officinalis on pyloric ligation-induced gastric ulcer in rats, the gastric juice and blood samples of rats in different administration groups were analyzed by Zaghlool et al. ${ }^{[39,40]}$ They found that oral administration with $A$. officinalis (100 $\mathrm{mg} / \mathrm{kg} /$ day) for $14 \mathrm{~d}$ could significant decrease ulcer number and ulcer index. Meanwhile, all blood and tissue parameters were significantly corrected by varying degrees.

\section{Wound healing effects}

The wound healing effects of $A$. officinalis was reported in previous studies. Rezaei et al. ${ }^{[35]}$ found the topical administration of hydroalcoholic extracts of $A$. officinalis leaves could accelerate the wound healing processes and increase the wound healing percent on excision wound model in rats. An investigation on flower mucilage ointment of $A$. officinalis displayed that the $15 \%$ flower mucilage significantly enhanced wound healing and reduced the days needed for complete healing compared with the non-treated groups in rabbits. ${ }^{[41]}$ Moreover, the $A$. officinalis aqueous extracts incorporated into a nanofibrous scaffold prepared by electrospinning the blend of poly ( $\varepsilon$-caprolactone) and gelatin could better exert the healing effects. ${ }^{[42]}$

\section{Other pharmacological effects}

A. officinalis extracts administration exhibited neuroprotective effects against 6-hydroxydopamine (6-OHDA)-induced hemi-Parkinsonism in rats. ${ }^{[4]} 10 \mathrm{mg} / \mathrm{kg}$ aqueous extracts of $A$. officinalis leaves might attenuate rotational behavior in the 6-OHDA administered group and protect the neurons of substantia nigra pars compacta.

\section{Conclusion and Perspective}

In summary, as a traditional folk medicinal plant, $A$. officinalis is widely distributed and easy to obtain. With the efforts made by researchers in recent years, many chemical components of $A$. officinalis, including flavonoids, polysaccharides, phenolic acids, coumarins and steroids, have been identified by various chromatographic methods. The diversity of the chemical constituents of the plant helps to explain the diverse pharmacological properties such as anti-tussive, anti-inflammatory, anti-oxidant, anti-bacterial and anti-fungal effects, etc. However, the current researches on the mechanism of the bioactive components and the active ingredients related to the therapeutic effects of $A$. officinalis are very limited, which greatly hinders its application in health care 
products. To better utilize the resources of $A$. officinalis, it is necessary to further study the active compositions and its molecular mechanism in detail.

\section{Acknowledgement}

This work was supported by the Shaanxi Province Science and Technology Overall Planning and Innovation Project Plan (No. 2016KTTSSF01-06-01) and the Special Fund Project for the Construction of Modern Agricultural Industrial Technology System (CARS-21).

\section{Conflict of Interest}

The authors declare no conflict of interest.

Copyright (0) 2021 Tao-Tao Xue, Hong-Bo Xu, Zhi-Shu Tang, Jin-Ao Duan, Hong-Bo Liu, Xin-Bo Shi, and Zhong-Xing Song. This article is an open access article distributed under the terms and conditions of the Creative Commons Attribution (CC BY) license (http://creativecommons. org/licenses/by/4.0/). The use, distribution or reproduction in other forums is permitted, provided the original author(s) or licensor are credited and that the original publication in this journal is cited, in accordance with accepted academic practice. No use, distribution or reproduction is permitted which does not comply with these terms.

\section{References}

[1] Fahamiya, N.; Shiffa, M.; Aslam, M.; Muzn, F. Unani perspective of Khatmi (Althaea officinalis). J. Pharmacogn. Phytochem. 2016, 6, 357-360.

[2] Pakrokh Ghavi, P. Modeling and optimization of ultrasoundassisted extraction of polysaccharide from the roots of Althaea officinalis. J. Food Process. Preserv. 2015, 39, 2107-2118.

[3] Shah, S. M. A.; Akhtar, N.; Akram, M.; Shah, P. A.; Saeed, T.; Ahmed, K.; Asif, H. M. Pharmacological activity of Althaea officinalis L. J. Med. Plants Res. 2011, 5, 5662-5666.

[4] Gudej, J. Flavonoid compounds of Althaea officinalis leaves. I. Glucoside esters, monoglucosides. Acta Pol. Pharm. 1985, 42, 192-198.

[5] Gudej, J. Flavonoid compounds of Althaea officinalis leaves. II. Glycosides of 8-hydroxyluteolin (hypoletin). Acta Pol. Pharm. 1987, 44, 369-373.

[6] Didry, N.; Torck, M.; Pinkas, M. Polyphenolic compounds from the flowers of Althaea officinalis. Fitoterapia 1990, 61, 280.

[7] Sendker, J.; Boker, I.; Lengers, I.; Brandt, S.; Jose, J.; Hensel, A.; Stark, T.; Hofmann, T.; Fink, C.; Abdel-Aziz, H. Phytochemical characterization of low molecular weight constituents from marshmallow roots (Althaea officinalis) and inhibiting effects of the aqueous extract on human hyaluronidase-1. J. Nat. Prod. 2017, 80, 290-297.

[8] Ninov, S.; Ionkova, I.; Kolev, D. Constituents of Althaea officinalis var. "Russalka" roots. Fitoterapia 1992, 63, 474.

[9] Gudej, J. Flavonoids, phenolic acids and coumarins from the roots of Althaea officinalis. Planta Med. 1991, 57, 284-285.

[10] Rani, S.; Khan, S. A.; Ali, M. Phytochemical investigation of the seeds of Althaea officinalis L. Nat. Prod. Res. 2010, 24, 1358-1364.

[11] Zoobi, J.; Mohd, A. Three new compounds from the roots of Althaea officinalis L. Int. J. Res. Ayurveda Pharm. 2011, 2, 864-868.

[12] Kardosova, A.; Capek, P.; Rosik, J. 4-O-methyl-D-glucurono- $D$ xylan from the leaves of the marsh mallow (Althaea-officinalis $\mathrm{L}$, var. rhobusta). Chem. Pap. 1989, 43, 705-713.

[13] Kardosova, A.; Malovikova, A.; Rosik, J.; Capek, P. Distribution pattern of 4-O-methyl- $D$-glucuronic acid units in 4-O-methyl- $D$ glucurono- $D$-xylan isolated from the leaves of marshmallow (Althaea officinalis L., var. rhobusta). Chem. Pap. 1990, 44,
$111-117$.

[14] Capek, P.; Toman, R.; Rosik, J.; Kardosova, A.; Janecek, F. Polysaccharides from the roots of Althaea officinalis L.: structural features of D-glucans. Collect. Czech. Chem. Commun. 1984, 49, 2674-2679.

[15] Capek, P.; Toman, R.; Kardosova, A.; Rosik, J. Polysaccharides from the roots of the marshmallow (Althaea officinalis L.): structure of an arabinan. Carbohydr. Res. 1983, 117, 133-140.

[16] Kardosova, A.; Rosik, J.; Toman, R.; Capek, P. Glucan isolated from leaves of Althaea officinalis L. Collect. Czech. Chem. Commun. 1983, 48, 2082-2087.

[17] Tomoda, M.; Satoh, N.; Shimada, K. Plant mucilages. XXIV. The structural features of althaea-mucilage $O$, a representative mucous polysaccharide from the roots of Althaea officinalis. Chem. Pharm. Bull. 1980, 28, 824-830.

[18] Basch, E.; Ulbricht, C.; Hammerness, P.; Vora, M. Marshmallow (Althaea officinalis L.) monograph. J. Herb. Pharmacother. 2003, 3, 71-81.

[19] Fink, C.; Schmidt, M.; Kraft, K. Marshmallow root extract for the treatment of irritative cough: two surveys on users' view on effectiveness and tolerability. Complement. Med. Res. 2018, 25, 299-305.

[20] Mahboubi, M. Marshmallow (Althaea officinalis L.) and its potency in the treatment of cough. Complement. Med. Res. 2019, 27, 1-9.

[21] Sutovska, M.; Nosalova, G.; Franova, S.; Kardosova, A. The antitussive activity of polysaccharides from Althaea officinalis L., var. robusta, Arctium lappa L., var. herkules, and Prunus persica L., Batsch. Bratis/ Lek Listy. 2007, 108, 93-99.

[22] Sutovska, M.; Capek, P.; Franova, S.; Joskova, M.; Sutovsky, J.; Marcinek, J.; Kalman, M. Antitussive activity of Althaea officinalis L. polysaccharide rhamnogalacturonan and its changes in guinea pigs with ovalbumine-induced airways inflammation. Bratis/ Lek Listy. 2011, 112, 670-675.

[23] Nosalova, G.; Strapkova, A.; Kardosova, A.; Capek, P. Antitussive activity of a rhamnogalacturonan isolated from the roots of Althaea officinalis L., Var. robusta. J. Carbohydr. Chem. 1993, 12, 589-596.

[24] Sutovska, M.; Nosalova, G.; Sutovsky, J.; Franova, S.; Prisenznakova, L.; Capek, P. Possible mechanisms of dose-dependent cough suppressive effect of Althaea officinalis rhamnogalacturonan in guinea pigs test system. Int. J. Biol. Macromol. 2009, 45, 27-32.

[25] Bonaterra, G. A.; Bronischewski, K.; Hunold, P.; Schwarzbach, H.; Kinscherf, R.; Heinrich, E.-U.; Fink, C.; Aziz-Kalbhenn, H.; Muller, J. Anti-inflammatory and anti-oxidative effects of phytohustil@ and root extract of Althaea officinalis $\mathrm{L}$. on macrophages in vitro. Front. Pharmacol. 2020, 11, 290.

[26] Benbassat, N.; Yoncheva, K.; Hadjimitova, V.; Hristova, N.; Konstantinov, S.; Lambov, N. Influence of the extraction solvent on antioxidant activity of Althaea officinalis L. root extracts. Cent. Eur. J. Biol. 2014, 9, 182-188.

[27] Zaghlool, S. S.; Abo-Seif, A. A.; Rabeh, M. A.; Abdelmohsen, U. R.; Messiha, B. a. S. Gastro-protective and anti-oxidant potential of Althaea officinalis and Solanum nigrum on pyloric ligation/ indomethacin-induced ulceration in rats. Antioxidants 2019, 8, 512.

[28] Elmastas, M.; Ozturk, L.; Gokce, I.; Erenler, R.; Aboul-Enein, H. Y. Determination of antioxidant activity of marshmallow flower (Althaea officinalis L.). Anal. Lett. 2004, 37, 1859-1869.

[29] Tabarsa, M.; Anvari, M.; Joyner, H. S.; Behnam, S.; Tabarsa, A. Rheological behavior and antioxidant activity of a highly acidic gum from Althaea officinalis flower. Food Hydrocolloids 2017, 69, 432-439.

[30] Tahmouzi, S.; Salek Nejat, M. R. New infertility therapy effects of polysaccharides from Althaea officinalis leaf with emphasis on characterization, anti-oxidant and anti-pathogenic activity. Int. J. Biol. Macromol. 2020, 145, 777-787.

[31] Sadighara, P.; Gharibi, S.; Jafari, A. M.; Jahed Khaniki, G.; Salari, S. 
The antioxidant and flavonoids contents of Althaea officinalis L. flowers based on their color. Avicenna J. Phytomed. 2012, 2, 113-117.

[32] Haghgoo, R.; Mehran, M.; Afshari, E.; Zadeh, H. F.; Ahmadvand, M. Antibacterial effects of different concentrations of Althaea officinalis root extract versus $0.2 \%$ chlorhexidine and penicillin on streptococcus mutans and lactobacillus (In vitro). J. Int. Soc. Prev. Community Dent. 2017, 7, 180-185.

[33] Aminnezhad, S.; Kermanshahi, R. K.; Ranjbar, R. Effect of Althaea officinalis extract on growth and biofilm formation in Pseudomonas aeruginosa. J. Pure Appl. Microbiol. 2016, 10, 1857-1863.

[34] Jafari-Sales, A.; Jafari, B.; Sayyahi, J.; Zohoori-Bonab, T. Evaluation of antibacterial activity of ethanolic extract of Malva neglecta and Althaea officinalis L. on antibiotic-resistant strains of Staphylococcus aureus. J. Biol. Today's World 2015, 4, 58-62.

[35] Rezaei, M.; Dadgar, Z.; Noori-Zadeh, A.; Mesbah-Namin, S. A.; Pakzad, I.; Davodian, E. Evaluation of the antibacterial activity of the Althaea officinalis $\mathrm{L}$. leaf extract and its wound healing potency in the rat model of excision wound creation. Avicenna J. Phytomed. 2015, 5, 105-112.

[36] Khamees, A. H.; Mutlag, S. H.; Al-Hilli, F. A.; Bahjat, A. A. Evaluation of antibacterial activity of aqueous and methanol extract of iraqi Althaea officinalis L. flowers on gastrointestinal key pathogens. Int. J. Pharm. Sci. Rev. Res. 2018, 48, 59-62.

[37] Valiei, M.; Shafaghat, A.; Salimi, F. Chemical composition and antimicrobial activity of the flower and root hexane extracts of Althaea officinalis in Northwest Iran. J. Med. Plants Res. 2011, 5, 6972-6976

[38] Gautam, S. S.; Navneet, Kumar, S.; Chauhan, R. Antimicrobial efficacy of Althaea officinalis L. seed extracts and essential oil against respiratory tract pathogens. J. Appl. Pharm. Sci. 2015, 5, 115-119.

[39] Zaghlool, S. S.; Shehata, B. A.; Abo-Seif, A. A.; Abd El-Latif, H. A. Protective effects of ginger and marshmallow extracts on indomethacin-induced peptic ulcer in rats. J. Nat. Sci., Biol. Med. 2015, 6, 421-428.

[40] Zaghlool, S. S.; Shehata, B. A.; Abo-Seif, A. A.; Abd El-Latif, H. A. Assessment of protective effects of extracts of Zingiber officinale and Althaea officinalis on pyloric ligation-induced gastric ulcer in experimental animals. UK J. Pharm. Biosci. 2015, 3, 48-57.

[41] Valizadeh, R.; Hemmati, A. A.; Houshmand, G.; Bayat, S. Bahadoram, M. Wound healing potential of Althaea officinalis flower mucilage in rabbit full thickness wounds. Asian Pac. J. Trop. Biomed. 2015, 5, 937-943.

[42] Ghaseminezhad, K.; Zare, M.; Lashkarara, S.; Yousefzadeh, M.; Aghazadeh Mohandesi, J. Fabrication of Althea officinalis loaded electrospun nanofibrous scaffold for potential application of skin tissue engineering. J. Appl. Polym. Sci. 2020, 137, 48587.

[43] Rezaei, M.; Alirezaei, M. Protective effects of Althaea officinalis L. extract in 6-hydroxydopamine-induced hemi-Parkinsonism model: behavioral, biochemical and histochemical evidence. J. Physiol. Sci. 2014, 64, 171-176.

Received February 12, 202

Accepted May 9, 202 